\title{
Preyssler Acid: A Mild and Efficient Catalyst for the Protection Alcohols with Dihydropyran
}

\author{
N. Feizi, ${ }^{*}$ H. Hassani, and M. Hakimi ${ }^{\dagger}$ \\ Department of Chemistry, Payam Noor University, Mashhad,Iran. EE-mail:feizi_n@pnu.ac.ir \\ ${ }^{\dagger}$ Department of Chemistry, Payam Noor University, Fariman, Iran \\ Received July 29, 2005
}

Key Words : Alcohol, Dihydropyran, Protection, Catalyst, Preyssler acid

Selective protection of hydroxyl groups in molecules containing multiple hydroxyl functions is an important reaction in organic synthesis. ${ }^{1}$ The protected hydroxyl group is stable under a variety of reaction conditions such as strongly basic media, reactions involving Grignard reagents and lithium alkyls, reduction with hydrides, oxidations, oxidative alkylations, acetylation reactions etc. ${ }^{2}$ Therefore there is always a demand for selective reagents for such purposes. This becomes more important when the reagents are available, simple to operate, selective and easy to handle.

3,4-Dihydro-2-H-pyran is one of the most widely used protecting groups in the multi-step organic synthesis and widespread synthetic applications for the protection of hydroxyl functions. A variety of protonic as well as Lewis acid catalysts have been developed for tetrahydropyranylation of hydroxy functions such as acidic Clay, ${ }^{3}$ Tos-OH, ${ }^{4}$ bis[trimethylsilyl]sulfate, ${ }^{5}$ trimethyliodosilane, ${ }^{6} \quad \mathrm{CuCl}_{2},{ }^{7}$ $\mathrm{DDQ},{ }^{8} \quad \mathrm{BF}_{3} \cdot \mathrm{OEt}_{2},{ }^{9}$ triphenylphosphine hydrobromide, ${ }^{10}$ $\mathrm{Ru}\left(\mathrm{CH}_{3}\right)_{3}$ (triphos) $](\mathrm{OTf})_{2},{ }^{11} \mathrm{I}_{2}{ }^{12}$ and silica chloride, ${ }^{13}$ some supported reagents such as $\mathrm{BF}_{3} \cdot \mathrm{OEt}_{2}$ and $\mathrm{Al}_{2}\left(\mathrm{SO}_{4}\right)_{3}$ on silica gel ${ }^{14}$ and ionic liquids. ${ }^{15}$ However, many of these procedures suffer from using expensive reagents, high temperatures, strongly acidic conditions, and the necessity for aqueous work-up and unavailability of the catalyst or the reagent. Consequently, introduction of a new method for the protection of alcohols by 3,4-dihydro 2-H-pyran (DHP) in neutral media is a useful contribution for this purpose.

Polyoxometalates have proved to be good catalysts for various oxidations. They are applied in bulk or supported forms, and both homogeneous and heterogeneous catalyses are possible. Due to their acidic and redox properties, heteropoly compounds (heteropoly acids and salts) are useful and versatile catalysts in a number of transformations. Since they exhibit weak superacidic properties, they can be used in reactions requiring electrophilic catalysis. ${ }^{16-19}$

Having these factors in mind, we now wish to report that preyssler acid $\left(\mathrm{H}_{14} \mathrm{NaP}_{5} \mathrm{~W}_{30} \mathrm{O}_{110}\right)^{20}$ is an excellent and effec-

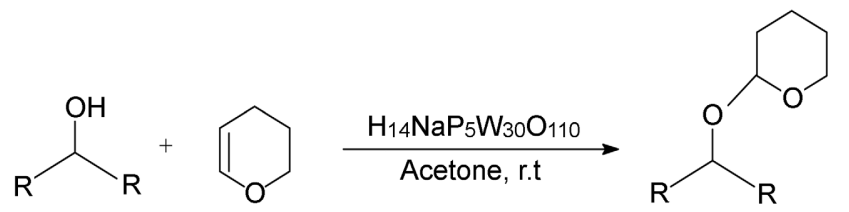

Scheme 1 tive catalyst for tetrahydropyranylation various of alcohols at room temperature. (Scheme 1, Table 1)

In this study, we have shown that primary and secondary hydroxy groups of benzylic alcohols substituted with electron-donating and electron-withdrawing groups can be effectively protected in the presence of preyssler acid $\left(\mathrm{H}_{14} \mathrm{NaP}_{5} \mathrm{~W}_{30} \mathrm{O}_{110}\right)(0.01$ equivalents) to their corresponding tetrahydropyranyl ethers in high yields. Cinnamyl alcohol was efficiently converted to the corresponding tetrahydropyranyl ether in excellent yields without isomerization of the C-C double bonds (Entry 6). Primary and secondary acyclic and cyclic saturated alcohols were also effectively transformed to their tetrahydropyranyl ethers with high yields (Entry 9-12). In the presence of this catalyst, phenol and phenols carrying electron-donating and electron-withdrawing groups were tested.

Phenol and 4-methyl phenol were converted to their corresponding ethers in low yields in high reaction times (Entry15, 16) but phenols carrying electron-withdrawing groups such as $-\mathrm{NO}_{2}$ and $-\mathrm{COCH}_{3}$ can not be converted to corresponding ethers.

The method was also found to be highly selective for mono tetrahydropyranylation of diols (Entry 13, 14).

In conclusion, this methodology provides a useful alternative for the preparation tetrahydropyran ethers. The main advantages of our methodology are mild reaction conditions, easy work-up, short reaction time, high yield, high efficiency, quick and clean, economic viability of the reagent.

\section{Experimental Section}

General. Chemicals were purchased from Merck and Fluka Chemical Companies. Preyssler acid $\left(\mathrm{H}_{14} \mathrm{NaP}_{5} \mathrm{~W}_{30} \mathrm{O}_{110}\right)$ was prepared according to the reported procedures. ${ }^{20}$ All the products are known and were characterized by comparison of their physical data with those reported in the literature. IR spectra were run on a Shimadzu model 8300 FT-IR spectrophotometer. NMR spectra were recorded on a Bruker DPX100. The purity of the products and the progress of the reactions were accomplished by TLC on silica-gel poly gram SILG/UV254 plates or by a Shimadzu Gas Chromatograph GC-14A instrument with a flame ionization detector.

General procedure for the tetrahydropyranylation of alcohols. To a solution of alcohol $(10 \mathrm{mmol})$ in acetone (50 $\mathrm{mL})$ was added 3,4-Dihydro-2-H-pyran $(15 \mathrm{mmol})$ and 
Table 1. protection alcohols and phenol with DHP at present preyssler acid catalyst

\begin{tabular}{|c|c|c|c|c|c|c|c|c|c|}
\hline Entry & Substrate & Product & $\begin{array}{l}\text { Time } \\
(\mathrm{min})\end{array}$ & $\begin{array}{c}\text { Yield }^{a} \\
(\%)\end{array}$ & Entry & Substrate & Product & $\begin{array}{l}\text { Time } \\
(\mathrm{min})\end{array}$ & $\begin{array}{c}\text { Yield }^{a} \\
(\%)\end{array}$ \\
\hline 1 & & & 2 & 92 & 10 & & & 5 & 90 \\
\hline 2 & & & 2 & 91 & 11 & & & 20 & 85 \\
\hline 3 & & & 2 & 91 & 12 & & & 20 & 85 \\
\hline 4 & & & 3 & 94 & 13 & & & 20 & 80 \\
\hline 5 & & & 7 & 85 & 14 & & & 7 & 80 \\
\hline 6 & & & 5 & 90 & 15 & & & 120 & 20 \\
\hline 7 & & & 3 & 90 & 16 & & & 120 & 20 \\
\hline 8 & & & 3 & 93 & 17 & & & N.R & - \\
\hline 9 & & & 5 & 88 & 18 & & & N.R & - \\
\hline
\end{tabular}

${ }^{b}$ Isolated yields.

$\mathrm{H}_{14} \mathrm{NaP}_{5} \mathrm{~W}_{30} \mathrm{O}_{110}(0.01$ equiv $)$ and the resulting mixture was stirred at room temperature. The progress of the reaction was monitored by TLC. After completion the reaction, the catalyst was removed by filtration and washed with acetone $(20 \mathrm{~mL})$. The solvent was evaporated under reduced pressure and the residue was further purified by column chromatography on silica gel.

Acknowledgements. The authors are thankful to the Payam Noor University of Mashhad and Fariman for the support of this work.

\section{References}

1. Eqbal, J.; Srivastava, R. R.; Gupta, K. B.; Amin Khan, M. Synth. Commun. 1989, 19, 901.

2. Bhalerao, U. T.; Joju Davis, K.; Vittal Rao, B. Synth. Commun. 1996, 26, 3081

3. Hoyer, S.; Laszlo, P. Synthesis 1986, 655.

4. Miyashita, M.; Yoshikoshi, A.; Grieco, P. A. J. Org. Chem. 1977, 42,3772 .

5. Morizawa, Y.; Mori, I.; Hiyama, T.; Nozaki, H. Synthesis 1983, 899.

6. Olah, G. A.; Husain, A.; Sigh, B. P. Synthesis 1985, 703.

7. Bhalerao, U. T.; Joji Davis, K.; Vittal Rao, B. Synth. Commun. 1996, 26, 3081 .

8. Tanemura, K.; Horaguchi, T.; Suzuki, T. Bull. Chem. Soc. Jpn. 1992, 65, 304.
9. Alper, H.; Dinkes, L. Synthesis 1972, 81.

10. Bolitt, V.; Mioskowski, C.; Shin, D. S.; Falck, J. R. Tetrahedron Lett. 1988, 29, 4583.

11. Ma, S.; Venanzi, L. M. Tetrahedron Lett. 1993, 34, 5269.

12. Deka, N.; Sarma, J. C. J. Org. Chem. 2001, 66, 1947.

13. Ravindranath, N.; Ramesh, C.; Das, B. Synlett 2001, 1777 and references cited therein

14. Ranu, B. C.; Saha, M. J. Org. Chem. 1994, 59, 8269; (b) Nishiguchi, T.; Kawamine, K. J. Chem. Soc., Chem. Commun. 1990, 1766.

15. Branco, L. C.; Afonso, C. A. M. Tetrahedron 2001, 57, 4405.

16. Misono, M. Stud. Surf. Sci. Catal. 1993, 75, 69.

17. Izumi, C.; Urabe, Y.; Onaka, M. Zeolite, Clay and Heteropoly Acid in Organic Reactions; Kodansha: Tokyo/ VCH: New York, 1993; Chapter 3.

18. Habibi, M. H.; Tangestaninejad, S.; Mohammadpoor-Baltork, I.; Mirkhani, V.; Yadollahi, B. Tetrahedron Lett. 2001, 42, 2851.

19. (a) Firouzabadi, H.; Iranpoor, N.; Amani, K. Green Chem. 2001, 3, 131. (b) Firouzabadi, H.; Iranpoor, N.; Amani, K. Synthesis 2002, 59. (c) Firouzabadi, H.; Iranpoor, N.; Amani, K. Synthesis 2003, 408. (d) Firouzabadi, H.; Iranpoor, N.; Nowrouzi, F.; Amani, K. Chem. Commun. 2003, 764. (e) Firouzabadi, H.; Iranpoor, N.; Nowrouzi, F.; Amani, K. Tetrahedron Lett. 2003, 44, 3951. (h) Firouzabadi, H. N.; Iranpoor, F.; Nowrouzi, F. Tetrahedron Lett. 2003, 44, 53.

20. (a) Preyssler, C. Bull. Soc. Chem. Fr 1970, 30. (b) Alizadeh, M. H.; Harmalker, S. P.; Jeanin, Y.; Pope, M. T. J. Am. Chem. Soc. 1985, 107, 2662. (c) Alizadeh, M. H.; Razavi, H.; Farrash Bamoharram, F.; Hassanzadeh, M. K.; Khoshnavazi, R.; Mohammadizonoz, F. Kinetics \& Catalysis 2003, 44, 524 